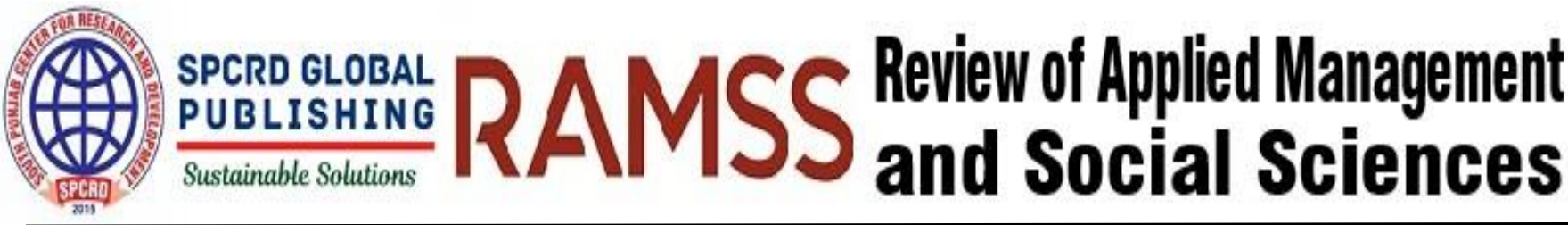

\section{The Impact of Extrinsic and Intrinsic Motivation on Employee Engagement: An Empirical Study of Health Care Sector of Punjab, Pakistan}

\author{
a Abou Bakar, ${ }^{\text {b }}$ Abdul Hameed, c Aasir Ali, d Muhammad Imran \\ ${ }^{a}$ Associate Professor, Management Sciences, The Islamia University of Bahawalpur, Bahawalnagar Campus: \\ abou.bakar@iub.edu.pk \\ ${ }^{\mathrm{b}}$ Assistant Professor, Management Sciences, The Islamia University of Bahawalpur, Bahawalnagar Campus: \\ abdul.hameed@iub.edu.pk \\ c Lecturer, Noon Business School, University of Sargodha: aasir.ali@uos.edu.pk \\ d Visiting Faculty, Management Sciences, The Islamia University of Bahawalpur, Bahawalnagar Campus: ctsc48@gmail.com
}

Corresponding author's email address: abou.bakar@iub.edu.pk

\begin{tabular}{l}
\hline ARTICLE DETAILS \\
\hline History: \\
Accepted 20 December 2019 \\
Available online 31 December 2019 \\
\hline Keywords: \\
Employees, workforce, \\
Motivation, Extrinsic Motivation, \\
Intrinsic Motivation, Employees' \\
Engagement. \\
\hline JEL Classification: \\
J24, J54, J28
\end{tabular}

DOI: $10.47067 /$ ramss.v2i2.18

\begin{abstract}
The purpose of this study is to find extrinsic and intrinsic motivation that has positive impact on employee's engagement. The study was conducted in the health care sector in Pakistan. A sample size of 100 employees was selected using convenient sampling techniques. The data were collected from doctors, nurses and managerial level of employees. 100 questionnaires were distributed among these employees out of whom 80 filled questionnaires were received forming percentage of $80 \%$. These properly filled questionnaires were used for data analysis. Data were analyzed through descriptive statistics, reliability analysis and regression analysis. Findings of the study reveal that there is significant relationship of extrinsic and intrinsic motivation on employee's engagements in the health care sector of Pakistan.
\end{abstract}

(C) 2019 The authors. Published by SPCRD Global Publishing. This is an open access article under the Creative Commons Attribution-

NonCommercial 4.0

\section{Introduction}

The impact Nowadays, Organizations are articulating an amalgamation of provisional and continuing strategy intended for efficient employees Motivation. Numerous types of Motivation gear (Rewards) are being set in sort to improve the efficiency of employees throughout their Engagement in particular job roles. However, permission has been recently superior for switching Money-for-Motivation to determined Employees' Engagement strategy. It has also been clear that an incorporation of Motivation (Extrinsic and Intrinsic) can establish to be useful equipment for ahead superior Employees' Engagement (Silvera, 2013). The word "Motivation" factually means, "To make something/someone to move". 
Employees are the vital components of all organization, irrespective of the organization being publicowned, private, or state-owned. Workforce/Employees perform their job duty for some Motivation. In addition is the ability and readiness to move. When an important person is mobilize and get-to-go towards a certain landmark is regard as "Motivated", while, a human being who do not have stimulation to act in a certain way, is careful as disinclined to move, thus regard as Un-Motivated (Deci \& Ryan, 200o). Furthermore, human beings are like icebergs, for the cause that higher piece of an iceberg is able to be seen, while the inferior part, that is below the exterior of water is not able to be seen (Kamel et al., 2006).

Now Motivation is further divided into two key sets i.e. Extrinsic Motivation and Intrinsic Motivation. Intrinsic Motivation is bring about from inner, deep-down value of the role-duties, for the specific human being (for example, interesting work itself, feedback, recognition).While Extrinsic Motivation originate from the wish to obtain some fabric outcome such as commission, bonus, pay raise etc, that are completely divisible from the course of work itself (Jiming \& Xinjian, 2013).

Hence, Employees require both; The Intrinsic Motivation and Extrinsic Motivation (Kamal et al., 2006). Employee Engagement is an advance, pleasant, on-the-job state of intelligence which consists of vigorousness, attachment, enthusiasm, and fascination (Schaufeli \& Bakker, 2004). There is a clear number of definitions defining Employee Engagement, which exerts more highlight on deliberation of Engagement either with managerial standpoint or with employee's perception (McBain, 2007).

The purpose of this study is to find out the impact of extrinsic and intrinsic motivation on employee's engagements in the health care sector of Punjab, Pakistan. Limited study is available regarding the impact of extrinsic and intrinsic motivation on employee's engagement so the aim of this study is to explore the impact of extrinsic and intrinsic motivation on employee's engagements in the health care sector of Punjab, Pakistan.

This study is conducted in the health care sectors of Punjab, Pakistan to find out the impact of extrinsic and intrinsic motivation on doctors, nurses and managerial staff. From the literature most of the researchers argued that extrinsic and intrinsic motivation has positive impact on employee's engagement.

\section{LITERATURE REVIEW}

\subsection{Motivation}

The term "Motivation" has been copied from Latin word "Movere" carries honest sense as "to move, to behavior/execute something (Ryan \& Deci, 2000; Steer et al., 2004). Young's wrote "Motivation" for behaviors, earlier in 1933 for the very first time, in his book "Motivation of Behavior". Seconding Robbins, Motivation is "the leaning to apply superior levels of hard work on the path to managerial benchmark, provide the functional hard work have the potential to fulfill any particular need". It (Motivation) is moreover considered as the association between the personnel drama the role and the circumstances/ work location (Latham \& Pinder, 2005).

\subsection{Historical Development in Motivation}

Frederick W. Taylor and his associates' work on Scientific Management association has forever been regarded as a significant progress in this exacting field. Scientific Management used to be regarded as a financial prosperous for personnel and organizations as well. Since 1930s, community genius and management put on pathway allowing for the part of social and public influence upon one's behavior. In the 1950 decade, new philosophy concerning motivation residential, the compilation of this philosophy is known as Content Theories. This theoretical development was destined to cover the pathway to 
classification of factors associated to Motivation. Bloisi et al., (2007) elaborated Content Theories as "grounded on identifying explicit person wants and connecting the circumstances under which those requirements turns into behavior". Abraham Maslow exposed the pecking order "Maslow's hierarchy of Needs Theory" in the very decade, which was then re-visited by Alderfer, shrinking seven levels of need to three main categories of need i.e. Existence Needs, Relatedness Needs, and Growth Needs (Steers et al., 2004).

\subsection{Extrinsic Motivation and Intrinsic Motivation}

Outside motivation are called Extrinsic Motivations. By this definition "a model that builds up whenever any precise doing is approved out/task is performed to complete some distinguishable outcomes". When organizations plan to get a positive task done by their employees, they propose monetarist plunder and other border benefits to their individual workers/staff. Such rewards/reimbursement refer to extrinsic rewards in management language. Extrinsic Rewards

constitute Extrinsic Motivation. Extrinsic type of Motivation is given to workers, for it is a lawful, virtuous and natural reimbursement for everyday jobs executed and target achieved by staff. Another type of Motivation is Intrinsic Motivation. According to Remi (2001), survey from a number of research result concerning workers motivation have certified, employees automatically consider intrinsic motivational factors more motivating than that of extrinsic motivation. Extrinsic Motivation has dissimilarity to Intrinsic Motivation. It has a influenced dissimilarity because Intrinsic Motivation is defined as "transportation out a certain activity exclusively for the sake of enjoyment and pleasure from the action itself, not essentially for its touchable worth (Ryan, 2000). Certain set rewards comprehensive to workers can also be Intrinsic Motivations, as strengthening to connect themselves in certain behaviors/ tasks specific attitude for the role which are hard-to-fill (Deci, 2001). Citizens in universal; rather to perform personality-fit jobs, tasks that are matching to their inner-self. "Humans/ Employees are innerdirected i.e. when they find the tasks motivating or charming for them and well-matched with their internal characteristics, engage in the very job, for the attention and attraction of it."(Zhang \& Bartol 2010).

Restating Zhang (2010), Intrinsic Motivation is one of the majority appropriate and consistent influences on the creative-ability and innovativeness. Employees' intrinsic rewards move toward right away from tasks performs. Job Appreciation, Job Satisfaction and Interesting work or the meager sense that they helped a customer by providing manufactured goods or service. Intrinsic Motivated workers employ themselves in a task-role because they have self-interest in the mission roles, such employees/workers take pleasure in their jobs, hunt for new substitute ways of tackling commerce challenges, thus these workers are most in all probability anticipated to go an additional mile to recognize shortcoming and find ground-breaking way outs (Cooper \& Jayatilaka, 2010). Intrinsic type of Motivation originates from an assenting response towards tasks, behavior, facial appearance and SOPs of a job role. Intrinsically motivated workers connect themselves in the job role because of their own awareness in the tasks and facial exterior of job. Theoreticians have agreed upon regarding Intrinsic Motivation as a psychological state which consists of profound part-taking in a certain job roles. Enjoying/rejoicing the role associated tasks and behavior give workers a intelligence of appointment in the role, rather than merely moving out managerial operations. Internal/Intrinsic Motivation also helps workers in fulfillment of very requirements to pleasure. Intrinsically Motivated workforce render more attachment to the job duty for their own attention, as well as to look for substitute technique of resolving dissimilar complication happening in business (Cooper \& Jayatilaka, 2010). 
Extrinsic type of Motivation has a propensity to reduce intrinsic type of Motivation. According to meta-analysis by Deci (2011), where a suggestion was probed and the results showed that Extrinsic type of Motivation is likely to reduce Intrinsic type of Motivation. Furthermore, results elaborate that foresee concrete plunder reduce the desire for intrinsic type of Motivation, while accidental tangible plunder aren't departing to get worse Intrinsic Motivation.

The aim of illumination Extrinsic Motivation and Intrinsic Motivation is to discover which type motivation has an continuing relationship with Employee Engagement. Workforces regard as both types of Motivation as essential influencers for their individual jobs connected motivation. Several members of the workforce are careful to be additional in-lined with extrinsic motivation than intrinsic and vice versa. Some scholars recognized, Extrinsic Rewards have negative relationship with creativity and innovativeness of the employees, because Extrinsic Motivation power affects Social Loafing i.e. putting less energies while working in a set (Cooper, 2010).

\subsection{Extrinsic Motivational Factors}

\subsubsection{Job Security}

Security of Job is a famous, pertaining anxiety that has been addressed by previous researchers. Job Security is defined as "the predicted, probable powerfulness to hold the job role". Job Security is associated to employees' manner towards job. Further described, a negative reply by workforce was reported throughout a short-term downsizing stage but subsequent to the hack down, a substantial positivity was observed in attitude (Sora, et al., 2009). Security of the job is careful vital to get extended Employee Commitment.

\subsubsection{Good Wages}

Good Wages are regarded as key and considerable factor for employee motivation. Workforces' progressive performance and deprived wages cannot go longer jointly. series in employees' wage results in the increase of competence and efficiency (Taylor \& Taylor, 2010). Employee Satisfaction and good wages are positively associated dynamics. Employees' level of satisfaction on the job, multiplies whenever their personal organization raise their monetarist benefits/rewards (Miller, 1980).

\subsubsection{Promotions and Growth Opportunities}

Promotions and Growth opportunity feature tend to put positive impacts on the improvement of any particular organization. Setlzer (2010) commented in universal as "To be practically certain, of accomplishing a condition of liability, a man of ability put himself/herself carefully to his/her job roles and studies".

Employee Engagement mentions to; when member of the labor force are endeavored to dedicate, reveal faithfulness and are unreserved to their jobs. Promoting and vocation steps for the employees are probable to be successful influencers to get Positive Employee Engagement. Employees who receive evenhanded promotions and growth opportunity are motivated to have a higher level of appointment in their own jobs, than those who hardly ever have such facilitations.

\subsubsection{Recognition}

Recognition can be a differentiation, a greeting, support, thankfulness, or any financial remunerate. It is an assenting distinction given to member/members of the workforce, for on behalf of a optimistic performance. Organization plunders employees for the achievement of some predictable work approach succeeding in preferred result. Credits are usually given to as plunder to employees when they accomplish a quantify standard or meet a convinced goal. Recognitions can be formal (Period of devoted 
services awards), or hasty (Earnest Acknowledgments, Corporate Trophies), monetarist enticement etcetera. Recognitions act as channel to workforce efficiency. Progressive organization is conscious of the information; achieving their mission requires innovativeness, creativity and a single business model, which mainly comes from the workforce. Quoting Ash and Kay (2012) "Workforce performing arts well on the job role, must be given Recognitions. Workers are most probable to experience more esteemed for the job roles and unswerving to association when they are constantly documented.

\subsection{Intrinsic Motivational Factors}

\subsubsection{Interesting Work}

Attention in the job role is important for any job. The possessions of the job being concerned; acting a fundamental role in job overall outcomes. When workers are provided with fascinating work surroundings that would facilitate them to be occupied in the job, to glass case their self in the work role they are performing arts and vice versa. Engagement in the job by motivating Work creates a connection between member of the workforce, their personal jobs and with peers. Organizations that make easy their workforce by provided that attractive Work, are most likely to be winning to fully connect their employees in their job roles (Saks, 2011)

\subsubsection{Job Appreciations}

Job Appreciations has a straight connection to Job Engagement. Organizations can create affluent industry venture through inculcating Job Appreciations in their culture. On the different, workforce' confidence can be unfavorably precious by their non-positive sentiment, which can potentially cause organization to run with hostility (Fagley, 2012).

\subsubsection{Job Satisfaction}

Organizations have to merge, bring together, and direct jobs to satisfy individuals performing these jobs (Mahfood, 2012). Job Satisfaction have great importance in look upon to Employee Engagement for the motivation it is connected with progressive compensation, quality-assured role, job safety, fair promotions, series opportunity and knowledge and growth facilitations to workforce. "Employment in Europe" survey in 2002 reveal that employees' Satisfaction concerning the job is absolutely related to Job status and Job activities (Jones \& Sloane, 2007).

\subsubsection{Stress}

Stress is defined as "psychological or exciting worrying or distressing state happening as a response to aggressive externalities' power” (Rosas, 2011).

Nowadays, in profitable organization, employees are exerted heavy pressures upon, to bring about output along with excellence fulfillment to presentation principles, which results in pressurize labor force cognitively and sensibly. When such unconformities happen between workforce and organizations' management, it would potentially result in Stress and lack of involvement of workforce cognitively. Stress harmfully disturbs performance of workforce. 
Link between Extrinsic Motivational Influences and Motivational Theories

\begin{tabular}{ll}
\hline Extrinsic Motivational Factors & Linked Theories \\
\hline Good Wages & Maslow's hierarchy of Needs Theory \\
Job Security & Alderfer's ERG Theory \\
Promotions and Growth Opportunities & Herzberg's Two Factors Theory \\
Recognitions & Four Drive Theory \\
\end{tabular}

Link between Intrinsic Motivational Influences and Motivational Theories

Intrinsic Motivational Factors Linked Theories

Interesting Work

Appreciation

Job Satisfaction
Maslow's hierarchy of Needs Theory

Alderfer's ERG Theory

Herzberg's Two Factors Theory

\subsection{Employees' Engagement}

Employees' Engagement has determinedly being the center of concentration, for a lot of academicians and HR practitioners, for a substantial age. Employees' Engagement is connected to both: the Organization and Employees. Previous to receiving into deep psychoanalysis concerning Employee Engagement and its connected school of consideration, it is to think significance of HR Management's purpose to enumerate performance and transfer possessions through measuring KPIs.

Employees are considered as one of the most crucial asset/resource for any organization. Workers/Employees do not just take action upon the SOPs they are given, there are noticeable factors that influence employees' performance on the job which finally results into optimistic or unenthusiastic profitability. Hence, Employees' optimistic donation makes organizations gainful.

Employees' Engagement is “yielding/ devoting of workforce members' selves to their personal job roles; In order to be called an occupied workforce, members of the workforce must be engaged and spoken significantly, rationally and willingly while the theater their particular or widespread roles”. Employees' Engagement, in addition, is quoted as "personnel are taking part and ensuing satisfaction along with 
excited come up to for the job roles" (Andrew \& Sofian, 2012). Thus, approving to images, Employees' Engagement is the cognitive part-taking, devotion and workforces' promise to managerial mission and hallucination, supplemented by value formation.

Defiantly, Employees' Disengagement is the “division of oneself from their individual job roles; whenever labor force pulls out, isolate and distance itself from the role presentation concerning corporeal cognitive and moving magnitude throughout the course of job roles”. Referring to Kahn (1990) Employees' Engagement means workforces' ease of use with admiration to bodily, mental, and cognitive individuality throughout performance of any assigned role. Schaufeli et al, (2002) demonstrated Employees' Engagement as "an assenting, task-related, accomplish state of mind which is determined by vigorousness, keenness for work and amalgamation in the job role. Other deliberations disclose that Employee's Engagement is not a fleeting and accurate state, though it is more constantly, tirelessly, efficiently, and cognitively governed state which has no association to any unusual happening, possessions, persons or attitude". A numeral of scholars, academicians and practitioners stare Employees' Engagement defiantly, hence most expert has agreement on bearing in mind it a dissimilar and idiosyncratic concept that constitute behaviors, attitudes, emotion and understanding which are connected with labor force as a whole and as a particular job-doer (Saks, 2006). Reveals the conclusion of global Survey Research (2003), attractive workforce is a practice by which organization improve overall charity of their individual workforce, to increase a difficult level of production. Employees' Engagement is the merger of understanding, SOPs yielding behaviors and expressively animated attitudes of workforce towards organization. Employees' Engagement turn to have a helpful collision on duty workforce perform, which yield more speculation pending in, in the form of more customers and patrons, profit maximizing venture and protracted consumers' faithfulness. An escalate numeral of faithful clientele are a sign to have sold additional supplies, and have deliver more services from the same firm, creation continuing commerce alliance with appropriate reaction, results in organizations' usefulness and development (Andrew, 2012).

\subsection{Employees' Engagement; Theories and Models}

Although, there is a shortage of factual, and hypothetical development/contributions concerning Employees' Engagement. yet, two inventors have given model for Employees' Engagement. A quantitative study/analysis conducted by kahn (1990), interviewed the workforce of an association, concerning appointment and disconnection, bearing in mind the current employments circumstances. It was found to be 3 emotional setting that gives the managerial behaviors the excellence of being engaged or DisEngaged in job roles. Individuals' three circumstances are somberness, safety and dexterity. May et al., (2004) revisited Kahn's (1990), model, and reveled the meaningfulness, protected job and convenience, as key scope of Employees' Engagement. Saks (2006), argued that member of the labor force remain on interrogate their own self, relating to three major curiosity. i.e. a) is the significance and meaningfulness of this job role is destined for me? b) Is my refuge definite, while performing arts on this role? c) Am I available to this job role? Result also consisted of the specifics. Workforce turn to be further part-taking and their contribution with provided workplace circumstances, which facilitate labor force, judgment their job role significant, protected, and consider himself accessible for the job role. May et al., (2004) also certified the three dimensional model of significance, safety, and dexterity, tend to be positive development towards accomplishment of Employees' Engagement, to elevated degree. It was also elaborated that promotions and enlargement opportunity, and job-specific part of individual wealth are sanguine indicator of meaningfulness of the job, smooth announcement, interpersonal relations and satisfying culture indicate safety, while an nearby operation of particular workers to the place of work and job system are indicator of expediency. 
H1: There is a positive relationship between Extrinsic and Intrinsic Motivation on employee's

\subsection{Engagement}

On the basis of literature review the following conceptual model has been developed.

\section{Conceptual Framework}
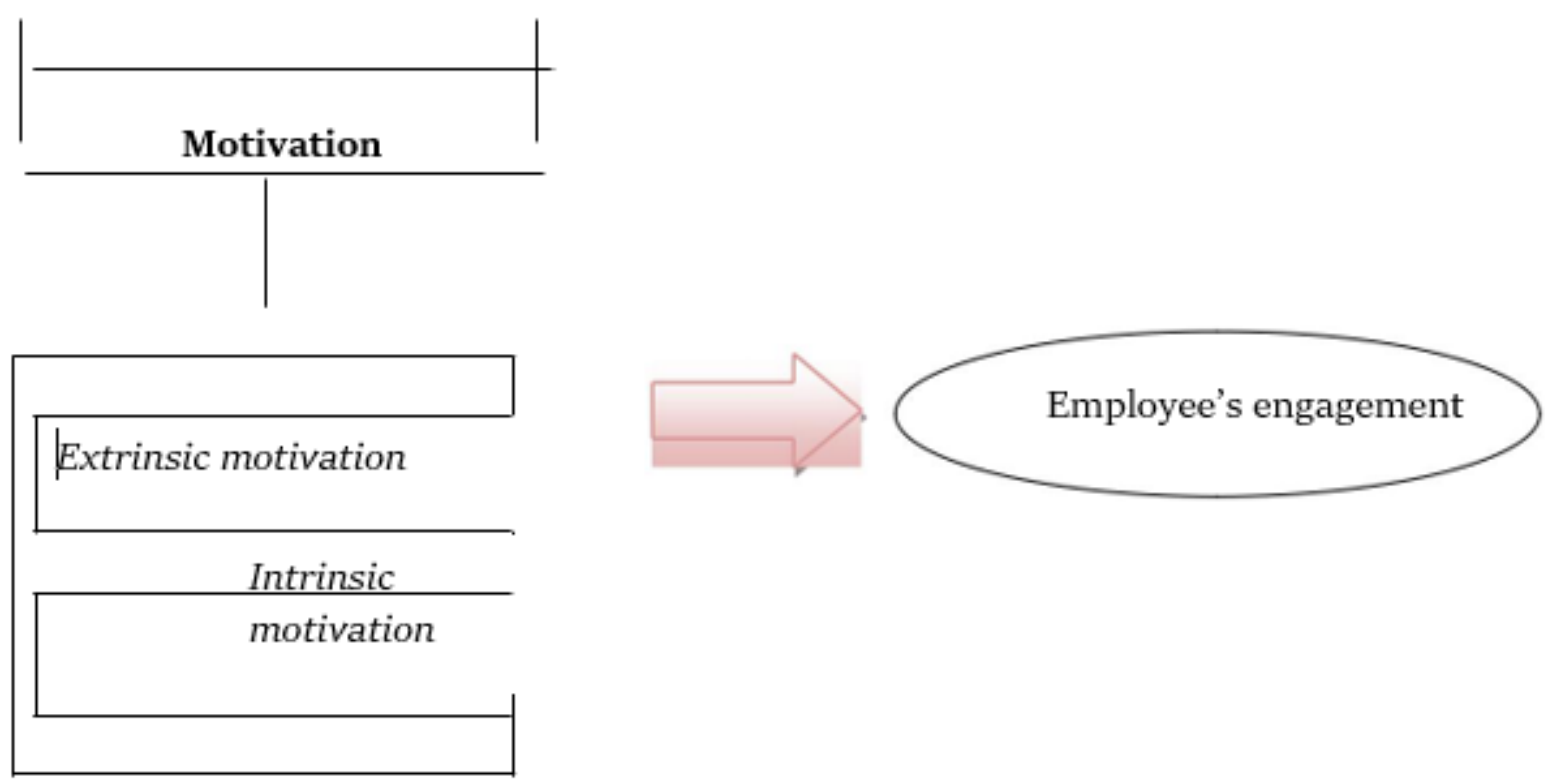

\section{RESEARCH METHODOLOGY}

\subsection{Data Collection}

With the help of self-administered questionnaires, the primary data were collected from all over the Punjab province of Pakistan. Data were collected via convenience sampling method. The data were collected from doctors, nurses and managerial level of employees. Major cities from where data were collected are Lahore, Rawalpindi, Multan, Faisalabad, Sargodha and Bahawalpur.

\subsection{Procedure and Statistical Methods}

100 close ended 5 point likert scale questionnaires were distributed among these employees out of whom 80 filled questionnaires were received forming percentage of $80 \%$ and these filled questionnaires were used for data analysis. Data was analyzed through SPSS version 20. Descriptive statistics, Reliability analysis and regression analysis was used for finding the relationship of role ambiguity on creative performance. This study was conducted in 12 weeks. 


\section{Sample Characteristics}

\begin{tabular}{lll}
\hline Demographic & Values & Frequency \\
\hline Gender & Male & 59 \\
Age (years) & Female & 21 \\
& $26-35$ & 14 \\
& $36-45$ & 36 \\
& $46-55$ & 14 \\
& $55^{+}$ & 16 \\
& & \\
City & & \\
& & \\
& Lahore & 21 \\
& Multan & 17 \\
& Rawalpindi & 15 \\
& Sargodha & 09 \\
& Faisalabad & 08 \\
& Others & 10 \\
& & \\
& &
\end{tabular}

Table 1: Sample Demographics

\section{Results}

The table 1 shows the number of items of motivation and employees' engagement. The number of items of motivation is 14 while employee's engagement contains on 6 numbers of items and 20 are the total number of items. According to the below table the Cronbach alpha for the motivation is 0.75 and for employees engagement is 0.71 , which shows that high level of consistency present in the variable. Hence the reliability statistics indicate that Cronbach alpha is approximately 0.72 for all variables, which also indicates that high consistency level present in the dependent and independent variable. The question consist in each variables indicated by " $\mathrm{N}$ of items". For each variable Cronbach alpha is given in the below table.

Table 1: Reliability statistics

Motivation

Employees engagement

Overall reliability
0.75

0.71

6 
The below table 2 shows descriptive statistics of the respondents. In this table the mean of gender is 0.52 while standard deviation is 0.50 . Similarly the respondent's qualification mean is 1.7 while standard deviation is 0.60 . In addition the mean of extrinsic motivation is 2.7 while standard deviation is 0.60 . Moreover, intrinsic motivation mean is 3.9 while standard deviation is 0.50 . The total numbers of respondents are 40.

Table 2: Descriptive statistics

\begin{tabular}{llll}
\hline & Mean & Std. Deviation & $\mathrm{N}$ \\
\hline Gender & .5250 & .50574 & 40 \\
Qualification & 1.7 & & 40 \\
Extrinsic Motivation & 2.7 & 0.60 & 40 \\
& & & \\
Intrinsic motivation & 3.9 & .62 & 40 \\
\hline
\end{tabular}

Table 3: Regression

The below table $3 \mathrm{R}$ shows the strength of relationship between the variables of the model. The value of $\mathrm{R}=0.779$ shows that there is $77.9 \%$ association between motivation and employees engagement. the extent of variance in the dependant variable due to variations in independent variable are shows by Adjusted R square. The value of Adjusted R square is 0.606 shows that motivation explains 60.6 variations in explaining employees engagement.

Table 3: Model Summary

\begin{tabular}{ccccc}
\hline Mode & & & & \\
1 & & & & \\
& & & Adjusted $\mathrm{R}$ & \\
& $\mathrm{R}$ & R Square & Square & Std. Error of the Estimate \\
& $.779 \mathrm{a}$ & .606 & .535 & .57211 \\
\hline
\end{tabular}

a. Predictors: (Constant), ages, MS Gender, Qualification, Extrinsic motivation, intrinsic motivation.

In the given table 4 the statistical significance of the model $(\mathrm{p}<.05)$ show by the value of $\mathrm{F}$. The $\mathrm{F}$ value is $8.464, \mathrm{p}=.000(\mathrm{p}<.05)$ sows the model is statistically significant. 
Table 4: ANOVA b

\begin{tabular}{lllrll}
\hline & Sum of & & & & \\
\hline Model & Squares & Df & Mean Square & F & Sig. \\
Regression & 16.622 & 6 & 2.770 & 8.464 & .0oob \\
Residual & 10.801 & 33 & .327 & & \\
Total & 27.423 & 39 & & & \\
& & & & & \\
\hline
\end{tabular}

a. Predictors: (Constant), engagement

b. Dependent Variable: Extrinsic

motivation, intrinsic motivation

\section{Table 5: Coefficients a}

The below table 4 shows the effect of individual independent variables on dependent variable. Whereas, the variables of age, gender, marital state and qualification are insignificant. Only the variables of Extrinsic and Intrinsic Motivation are significant, which means that they have a role in determining the Employees' Engagement.

Table 4 :Coefficients a

\begin{tabular}{|c|c|c|c|c|c|}
\hline \multirow[t]{3}{*}{ Model } & \multicolumn{2}{|c|}{ Unstandardized } & Standardized & \multirow[t]{2}{*}{$\mathrm{t}$} & \multirow[t]{2}{*}{ Sig. } \\
\hline & Coeffic & & Coefficients & & \\
\hline & & & Beta & & \\
\hline (Constant) & -.918 & .743 & & -1.236 & .225 \\
\hline Extrinsic Motivation & $\cdot 371$ & .167 & .276 & 2.218 & .034 \\
\hline Intrinsic Motivation & .927 & .190 & .599 & 4.872 & .000 \\
\hline Qualification & .111 & .158 & .080 & .698 & .490 \\
\hline MS & .059 & .262 & .032 & .224 & .824 \\
\hline Gender & .169 & .246 & .102 & .688 & .496 \\
\hline Age & .161 & .178 & -.114 & -.907 & .371 \\
\hline
\end{tabular}

a. Dependent Variable: Engagement

\section{Conclusion}

The study aimed at exploring the impact of extrinsic motivation and intrinsic motivation on employee's engagement. Staff receives different amounts of Extrinsic and Intrinsic rewards irrespective of the fact that the central part of the duties and responsibilities are the same. The results of the study 
show that there is a direct relationship between Extrinsic Motivation and Employee Engagement. There is also a considerable, more significant and affirmative relationship between Intrinsic Motivation and Employee Engagement. A considerable number of respondents were satisfied with the sum total of rewards while performing their job. But there were several of the respondents who responded negatively.

\section{References}

Andrew, O. C., \& Sofian, S. (2012). Individual factors and work outcomes of employee engagement. Procedia-Social and Behavioral Sciences, 40, 498-508.

Attridge, M. (2009). Measuring and managing employee work engagement: A review of the research and business literature. Journal of Workplace Behavioral Health, 24(4), 383398.

Chalofsky, N. E. (2010). Meaningful workplaces: Reframing how and where we work. John Wiley \& Sons.

Christian, M. S., Garza, A. S., \& Slaughter, J. E. (2011). Work engagement: A quantitative review and test of its relations with task and contextual performance. Personnel Psychology, 64(1), 89-136.

Cherian, J., \& Farouq, S. (2013). A review of human resource accounting and organizational performance. International Journal of Economics and Finance, 5(8), 74.

Cooper, R. B., \& Jayatilaka, B. (2006). Group creativity: The effects of extrinsic, intrinsic, and obligation motivations. Creativity Research Journal, 18(2), 153-172.

Dalal, R. S., Baysinger, M., Brummel, B. J., \& LeBreton, J. M. (2012). The relative importance of employee engagement, other job attitudes, and trait affect as predictors of job performance. Journal of Applied Social Psychology, 42(S1), E295-E325.Chicago

Dash, M., \& Mohanty, K. (2015). Investigating the relationship between Employee Involvement, Employee Empowerment and Employee Satisfaction in a large Manufacturing Environment. Asian Journal of Research in Social Sciences and Humanities, 5(7), 91.

Deci, E. L., Koestner, R., \& Ryan, R. M. (2001). Extrinsic rewards and intrinsic motivation in education: Reconsidered once again. Review of educational research, 71(1), 1-27.

Deci, E. L., \& Ryan, R. M. (1987). The support of autonomy and the control of behavior. Journal of personality and social psychology, 53(6), 1024 .

Deeprose, Donna. How to Recognize and Reward Employees: 150 Ways to Inspire Peak Performance. AMACOM Div American Mgmt Assn, 2006.

Denzin, N. K., \& Lincoln, Y. S. (2011). The SAGE handbook of qualitative research.

SageFagley, N. S., \& Adler, M. G. (2012). Appreciation: A spiritual path to finding value and meaning in the workplace. Journal of management, spirituality \& religion, 9(2), 167-187.

Iguisi, O. (2009). Motivation-related values across cultures. African Journal of Business Management, 3(4), 141 .

Ryan, R. M., \& Deci, E. L. (2000). Intrinsic and extrinsic motivations: Classic definitions and new directions. Contemporary educational psychology, 25(1), 54-67.

Schaufeli, Wilmar B., and Arnold B. Bakker. "Job demands, job resources, and their relationship with burnout and engagement: A multi-sample study." Journal of organizational Behavior. 25 (3), 293315 .

Tangthong, S. (2010). A causal model of compensation and benefits and reward management on organizational effectiveness of MNCs.

Wu, J., \& Lu, X. (2013). Effects of extrinsic and intrinsic motivators on using utilitarian, hedonic, and dual-purposed information systems: A meta-analysis. Journal of the Association for Information Systems, 14(3), 153. 